\title{
Education and the COVID-19 pandemic
}

\author{
Sir John Daniel ${ }^{1}$
}

Published online: 20 April 2020

(C) UNESCO IBE 2020

\begin{abstract}
The COVID-19 pandemic is a huge challenge to education systems. This Viewpoint offers guidance to teachers, institutional heads, and officials on addressing the crisis. What preparations should institutions make in the short time available and how do they address students' needs by level and field of study? Reassuring students and parents is a vital element of institutional response. In ramping up capacity to teach remotely, schools and colleges should take advantage of asynchronous learning, which works best in digital formats. As well as the normal classroom subjects, teaching should include varied assignments and work that puts COVID-19 in a global and historical context. When constructing curricula, designing student assessment first helps teachers to focus. Finally, this Viewpoint suggests flexible ways to repair the damage to students' learning trajectories once the pandemic is over and gives a list of resources.
\end{abstract}

Keywords curriculum $\cdot$ learning $\cdot$ teaching $\cdot$ assessment $\cdot$ COVID-19 $\cdot$ pandemic $\cdot$ crisis

The last 50 years have seen huge growth worldwide in the provision of education at all levels. COVID-19 is the greatest challenge that these expanded national education systems have ever faced. Many governments have ordered institutions to cease face-to-face instruction for most of their students, requiring them to switch, almost overnight, to online teaching and virtual education. This brief note offers pragmatic guidance to teachers, institutional heads and state officials who must manage the educational consequences of this crisis. It addresses:

- Preparations that systems could make

- Needs of students at different levels and stages

- Reassurance to students and parents

- Simple approaches to remote learning

Sir John Daniel

odlsirjohn@gmail.com

1 Acsenda School of Management, Vancouver, Canada 
- Curricula

- Assessment

- After COVID-19

- Useful resources.

\section{Preparations}

Most governments played catch-up to the exponential spread of COVID-19, so institutions had very little time to prepare for a remote-teaching regime. Where possible, preparations could have included:

- Ensuring that students took home the books, etc., needed for study at home.

- Tying up loose ends; e.g., finalizing test results and reports. In the northern hemisphere, many schoolteachers were in the process of predicting grades of year-end exams for submission with students' applications to tertiary education. Depending on whether they made them before or after the formal suspension of these exams, teachers' predictions may have been different, creating anxiety for both themselves and their students.

- Staff preparation and training: arrangements for safeguarding; division of work between departments; mechanisms for teachers to remain in touch collectively for mutual support; and brief and simple updates on learning technologies already somewhat familiar. Many institutions had plans to make greater use of technology in teaching, but the outbreak of COVID-19 has meant that changes intended to occur over months or years had to be implemented in a few days.

\section{Different students, different needs}

The COVID-19 pandemic has disrupted the lives of students in different ways, depending not only on their level and course of study but also on the point they have reached in their programmes. Those coming to the end of one phase of their education and moving on to another, such as those transitioning from school to tertiary education, or from tertiary education to employment, face particular challenges. They will not be able to complete their school curriculum and assessment in the normal way and, in many cases, they have been torn away from their social group almost overnight. Students who make the transition to tertiary education later this year are unlikely to take up offers to sit their year-end school exams (e.g., the International Baccalaureate) in a later session.

Even those part-way through their programmes will be anxious until they have clear indications of how their courses and assessment schemes will be restored after the crisis. Many in the COVID-19 cohort of students will worry about suffering long-term disadvantages, compared to those who studied "normally", when they move to another level of study or enter the labour market. Statements from tertiary institutions that they will apply admission criteria "compassionately" may not always reassure.

While approaches to remote learning will clearly differ as between elementary (primary) school and tertiary education, the needs of skills-sector programmes (Technical and Vocational Education and Training-TVET) need special attention. The graduates of such programmes will have a key role in economic recovery. Providing the practical training they require through distance learning is possible but requires special arrangements. 
The Commonwealth of Learning is a useful point of reference for TVET in developing countries.

\section{Reassurance to students and parents}

These are anxious times for students and parents. Uncertainties about when life will return to "normal" compound the anxiety. Even as institutions make the changes required to teach in different ways, all should give the highest priority to reassuring students and parentswith targeted communication. Many teachers and counsellors will have to provide this reassurance without clear information from examining bodies and institutions about the arrangements for replacing cancelled examinations and modifying admissions procedures. Institutions should update students and parents with frequent communication on these matters. Teachers and school counsellors may be better than parents at assuaging the anxieties of students in deprived situations. All, however, can access help lines and resources outside the school system that specialize in addressing emotional and psychological challenges.

Fifty years ago, various jurisdictions created "open" universities in order to equalize opportunity by extending access to tertiary education through distance learning. Sadly, the current imperative of continuing schooling by hasty transitions to remote learning may have the opposite impact. Institutions and educational systems must make special efforts to help those students whose parents are unsupportive and whose home environments are not conducive to study. Where households are confined to their residences by COVID-19, parents and guardians may be deeply anxious about their own economic future, so studying at home is not easy, especially for children with low motivation. Such homes often lack the equipment and connectivity that richer households take for granted, compounding the problem.

\section{Simple approaches to remote teaching: Use asynchronous learning}

Just as institutions take steps to inform, reassure and maintain contact with students and parents, they must also ramp up their ability to teach remotely. This emergency is not the time to put into effect complex institutional plans for distance learning that were meant to be implemented over months or years. The witticism that "if a job is worth doing, it's worth doing badly" has validity. Teachers should work with what they know. Giving full attention to reassuring students is more important than trying to learn new pedagogy or technology on the fly.

The most important adjustment, for those used to teaching in classrooms in real time, is to take advantage of asynchronous learning. For most aspects of learning and teaching, the participants do not have to communicate simultaneously. Asynchronous working gives teachers flexibility in preparing learning materials and enables students to juggle the demands of home and study. Asynchronous learning works best in digital formats. Teachers do not need to deliver material at a fixed time: it can be posted online for on-demand access and students can engage with it using wikis, blogs, and e-mail to suit their schedules. Teachers can check on student participation periodically and make online appointments for students with particular needs or questions. Creating an asynchronous digital classroom gives teachers and students more room to breathe. 
Similarly, video lessons are usually more effective - as well as easier to prepare - if they are short (5-10 minutes). Organizations offering large-enrolment online courses, such as FutureLearn, have optimized approaches to remote learning that balance accessibility and effectiveness. Anyone asked to teach remotely can log in to a FutureLearn course in their subject area to observe the use of short videos. Teachers might also wish to flag relevant online courses to their students.

\section{Curricula}

What curriculum should teachers use for remote learning during the COVID-19 crisis? The response will vary by jurisdiction. Some have prescriptive national curricula, whereas others give wide discretion to teachers to choose programme content. General advice is for teachers to keep two objectives in mind. While it is important to continue to orient students' learning to the classroom curriculum and the assessments/examinations for which they were preparing, it is also vital to maintain students' interest in learning by giving them varied assignments - not least, perhaps, by work that sets the present COVID-19 crisis in a wider global and historical context. Some schools are encouraging students to engage with the crisis by preparing hampers of food and supplies for vulnerable families or writing letters to elderly residents in care homes.

For such enrichment, teachers can draw on the abundance of high-quality learning material now available as freely usable Open Educational Resources. The OpenLearn website, for example, contains over 1,000 courses at both school and tertiary levels. There is no dishonour in teaching through good materials prepared by others.

\section{Assessment}

End-of-year examinations in the northern hemisphere have been cancelled or suspended by many examining bodies (e.g., the International Baccalaureate Organisation), with a knockon impact in the southern hemisphere. This has left millions of students, even those who do not relish examinations, feeling left in the lurch. At this moment (April 2020), as COVID19 still rages in most parts of the world, these bodies are unable to say when they will resume normal operations and how, if at all, they will provide results for this year's cohort.

Institutions versed in distance learning often start the process of course construction by designing the student assessments that will be part of it. This is a way of clarifying learning objectives and content that teachers making a sudden transition to remote operation should consider adopting. It will help them determine the parts of the standard curriculum on which they will focus as well as their aims in including other topics.

\section{After COVID-19}

Until countries can judge when the trade-off between economic activity and public health will enable them to ease restrictions on normal life, anxiety about the extent and duration of the special COVID-19 arrangements in each jurisdiction will continue. Moreover, the return to normality will not be a simple one-time transition to life as it used to be. 
Jurisdictions will assess risks differently and all will take precautionary measures against second and third waves of COVID-19 outbreaks.

Institutions, teachers, and students will continue to look for flexible ways to repair the damage caused by COVID-19's interruptions to learning trajectories. In this context, the open schools (e.g., India's National Institute of Open Schooling; the New Zealand Correspondence School) and open universities (e.g., The UK Open University; Athabasca University, Canada) - most of which have continued to operate through the COVID-19 pandemic - can sometimes provide the variety of courses and flexibility of time and place of learning to help students get back on track.

Although institutions that normally teach face-to-face in classrooms or on campuses will likely return to that mode of instruction with some relief, the special arrangements they put in place during the COVID-19 crisis will leave a lasting trace. The expansion of online learning in tertiary education will further accelerate, and schools will organize themselves more systematically to pursue the aspects of technology-based learning that they have found most useful.

All institutions will derive benefit from the mechanisms that they have put in place to continue their educational and training missions in a time of crisis.

\section{Resources}

This is a small selection of the huge array of resources on which educators wishing to adopt remote learning can draw. To put them in context:

- The Commonwealth of Learning is an intergovernmental agency of the Commonwealth tasked with helping developing countries use technology effectively in education and training at all levels. It focuses particularly on technology that is appropriate for resource-poor situations.

Commonwealth of Learning. (Skills training [TVET] for men and women): https:// www.col.org/programmes/technical-and-vocational-skills-development

Commonwealth of Learning. (Open Schooling): https://www.col.org/programmes/openschooling

- These references from David Gaertner and the Sacred Heart Schools bracket a range of responses to COVID-19, from "work with what you know" to carefully organised and gradual processes.

David Gaertner, \#COVIDCAMPUS: https://novelalliances.com/2020/03/16/covid campus/

Sacred Heart Schools: Flexible Plan for Instructional Continuity: https://tinyurl.com/ rrqfae7

- UNESCO has much experience in advising Member States how to adapt their educational systems to crises of various kinds.

UNESCO—Distance learning solutions: https://en.unesco.org/covid19/educationrespon se/solutions 
- The YTL Foundation is an example of national provision of online resources to teachers, parents, and students.

YTL Foundation, Malaysia: https://ytlfoundation.org/learnfromhome/

- FutureLearn and OpenLearn are important collections of online courses and course resources under the aegis of the UK Open University.

FutureLearn (free mass enrolment courses on many topics): https://www.futurelear n.com/

OpenLearn: Free learning from the Open University: https:/www.open.edu/openlearn/

- Open Schools: There are open schools offering flexible schooling to large numbers of pupils in various countries. Three examples are India (https://www.nios.ac.in/), Namibia (https://www.namcol.edu.na/), and New Zealand (https://www.tekura.school.nz/)

- Open Universities: Some 50 jurisdictions around the world have established open universities, which enroll millions of students between them. Three examples are Canada (https://www.athabascau.ca/, Tanzania (https://www.out.ac.tz/), and the United Kingdom (http://www.open.ac.uk/).

- Surrey County Council: Resources for families-examples of links recommended by an English regional government.

Talking to your child about coronavirus: https://youngminds.org.uk/blog/talking-toyour-child-about-coronavirus/

How to look after your family's mental health when you're stuck indoors: https://paren tinfo.org/article/how-to-look-after-your-family-s-mental-health-when-you-re-stuck-indoors

Keeping children happy and safe online during COVID-19: https://www.saferinternet. org.uk/blog/keeping-children-happy-and-safe-online-during-covid-19.

Publisher's Note Springer Nature remains neutral with regard to jurisdictional claims in published maps and institutional affiliations.

Sir John Daniel (Canada, United Kingdom) was educated at Christ's Hospital School and the Universities of Oxford and Paris. After completing degrees in Metallurgy, he taught at the École Polytechnique, Montréal before studies in Educational Technology led him to re-orient his career to open and distance education and take up appointments that included 17 years as a university president at Laurentian University, Ontario; and the UK Open University. After serving as Assistant Director-General for Education at UNESCO from 2001 to 2004, he moved to Vancouver as president of the Commonwealth of Learning in 2004. He was knighted in 1994, appointed to the Order of Canada in 2013, and holds 32 honorary doctorates from universities in 17 countries. His 390 publications include Mega-universities and Knowledge Media: Technology Strategies for Higher Education and Mega-Schools, Technology and Teachers: Achieving Education for All. 